\title{
Single $\mathrm{K}_{\mathrm{ATP}}$ Channel Opening in Response to Action Potential Firing in Mouse Dentate Granule Neurons
}

\author{
Geoffrey R. Tanner, Andrew Lutas, Juan Ramón Martínez-François, and Gary Yellen \\ Department of Neurobiology, Harvard Medical School, Boston, Massachusetts 02115
}

ATP-sensitive potassium channels ( $\mathrm{K}_{\mathrm{ATP}}$ channels) are important sensors of cellular metabolic state that link metabolism and excitability in neuroendocrine cells, but their role in nonglucosensing central neurons is less well understood. To examine a possible role for $\mathrm{K}_{\text {ATP }}$ channels in modulating excitability in hippocampal circuits, we recorded the activity of single $\mathrm{K}_{\mathrm{ATP}}$ channels in cell-attached patches of granule cells in the mouse dentate gyrus during bursts of action potentials generated by antidromic stimulation of the mossy fibers. Ensemble averages of the open probability $\left(p_{\text {open }}\right)$ of single $\mathrm{K}_{\mathrm{ATP}}$ channels over repeated trials of stimulated spike activity showed a transient increase in $p_{\text {open }}$ in response to action potential firing. Channel currents were identified as $\mathrm{K}_{\mathrm{ATP}}$ channels through blockade with glibenclamide and by comparison with recordings from Kir6.2 knock-out mice. The transient elevation in $\mathrm{K}_{\mathrm{ATP}} p_{\text {open }}$ may arise from submembrane ATP depletion by the $\mathrm{Na}^{+}-\mathrm{K}^{+}$ATPase, as the pump blocker strophanthidin reduced the magnitude of the elevation. Both the steady-state and stimulus-elevated $p_{\text {open }}$ of the recorded channels were higher in the presence of the ketone body R- $\beta$ hydroxybutyrate, consistent with earlier findings that ketone bodies can affect $\mathrm{K}_{\mathrm{ATP}}$ activity. Using perforated-patch recording, we also found that $\mathrm{K}_{\text {ATP }}$ channels contribute to the slow afterhyperpolarization following an evoked burst of action potentials. We propose that activity-dependent opening of $\mathrm{K}_{\mathrm{ATP}}$ channels may help granule cells act as a seizure gate in the hippocampus and that ketone-bodymediated augmentation of the activity-dependent opening could in part explain the effect of the ketogenic diet in reducing epileptic seizures.

\section{Introduction}

ATP-sensitive $\mathrm{K}^{+}$channels, or $\mathrm{K}_{\mathrm{ATP}}$ channels, are inward-rectifier potassium channels that are inhibited by intracellular ATP. Their role of linking metabolism to electrical activity is best understood in pancreatic beta cells, where their modest open probability between meals is sufficient to maintain a hyperpolarized state; upon ingestion of a sugary meal, the channels close, allowing action potentials to fire and produce $\mathrm{Ca}^{2+}$ influx and insulin release (Aguilar-Bryan and Bryan, 1999; Ashcroft and Gribble, 1999; Seino and Miki, 2003; Nichols, 2006). $\mathrm{K}_{\text {ATP }}$ channels can play a similar role in central glucosensing neurons (Ashford et al., 1990; Miki et al., 2001).

$\mathrm{K}_{\mathrm{ATP}}$ channels are also present in a large number of central neurons that do not have a primary glucosensing role (Karschin

Received Nov. 11, 2010; revised April 28, 2011; accepted May 4, 2011.

Author contributions: G.R.T., A.L., J.R.M.F., and G.Y. designed research; G.R.T., A.L., and J.R.M.F. performed research; G.R.T., A.L., J.R.M.F., and G.Y. analyzed data; G.R.T., A.L., J.R.M.F., and G.Y. wrote the paper.

This work was supported by NIH/NINDS Grants NS029693 and NS055031 to G.Y. We also received support for biostatistics consultation from Harvard Catalyst-The Harvard Clinical and Translational Science Center (NIH Grant RR025758 and financial contributions from Harvard University and its affiliated academic health care centers). The content is solely the responsibility of the authors and does not necessarily represent the official views of Harvard Catalyst, Harvard University and its affiliated academic health care centers, the National Center for Research Resources, or the National Institutes of Health. We thank members of the Yellen laboratory for valuable discussions and comments on the manuscript. We also thank Drs. Bruce Bean, Rachel Wilson, and Bernardo Sabatini for assistance and advice, and Dr. E. Andres Houseman for discussing statistical methods. NN414 was a gift from Novo Nordisk. Kir6.2 knock-out mice were generously provided by Drs. S. Seino and C. G. Nichols; we thank Tatiana Abramson for expert technical assistance in genotyping the mice and Drs. James Berg, Weiyuan Ma, and Mathew Tantama for assistance in colony maintenance.

Correspondence should be addressed to Dr. Gary Yellen, Department of Neurobiology, Harvard Medical School, 220 Longwood Avenue, Boston, MA 02115. E-mail: gary_yellen@hms.harvard.edu.

DOI:10.1523/JNEUROSCI.5951-10.2011

Copyright $\odot 2011$ the authors $\quad 0270-6474 / 11 / 318689-08 \$ 15.00 / 0$ et al., 1997; Dunn-Meynell et al., 1998; Zawar et al., 1999); in these neurons, as in the heart (Benndorf et al., 1991), the channels are mainly thought to remain closed except under conditions of severe metabolic deprivation, such as anoxia or ischemia. Inhibitors of $\mathrm{K}_{\mathrm{ATP}}$ channels can sometimes affect neuronal firing under less pathological circumstances (Pierrefiche et al., 1996; Allen and Brown, 2004), implying that some basal activity of $\mathrm{K}_{\mathrm{ATP}}$ channels can affect neuronal excitability in nonglucosensing neurons. But it remains largely undetermined if and how normal levels of neuronal firing, via the consequent metabolic load, can lead to $K_{\text {ATP }}$ channel opening. This possibility of activity-dependent $\mathrm{K}_{\mathrm{ATP}}$ channel opening is suggested by results from brainstem inspiratory neurons (Haller et al., 2001), where bursts of single $\mathrm{K}_{\mathrm{ATP}}$ channel opening are seen in synchrony with the respiratory firing rhythm; channel open probability $\left(p_{\text {open }}\right)$ is increased by $\sim 60 \%$ after a strong burst of action potentials, compared with immediately before. These changes are smaller with blockade of the $\mathrm{Na}^{+}-\mathrm{K}^{+}$ATPase, suggesting that ATP consumption in response to the $\mathrm{Na}^{+}$influx from action potentials contributes to the $\mathrm{K}_{\mathrm{ATP}}$ channel opening.

We examined the ability of action potentials to induce $\mathrm{K}_{\mathrm{ATP}}$ channel opening in the dentate granule neurons (DGNs) of the mouse hippocampus. These cells express a particularly high density of $\mathrm{K}_{\mathrm{ATP}}$ channels (Karschin et al., 1997; Zawar et al., 1999), such that single $\mathrm{K}_{\mathrm{ATP}}$ channels can be recorded in $\sim 50 \%$ of cellattached patch recordings (Pelletier et al., 2000). Because these cells have a very low rate of spontaneous firing in superfused hippocampal slices, we induced action potential firing by electrical stimulation of the DGN axons in the dentate hilus. We found that modest firing activity, a burst of five action potentials at 20 
$\mathrm{Hz}$, was adequate to increase the activity of single $\mathrm{K}_{\text {АтP }}$ channels for $0.5-1 \mathrm{~s}$. This effect on $\mathrm{K}_{\mathrm{ATP}}$ largely disappeared in the presence of strophanthidin, a blocker of the $\mathrm{Na}^{+}-\mathrm{K}^{+}$ATPase. It appears that even moderate action potential firing can evoke $\mathrm{K}_{\text {ATP }}$ channel opening via $\mathrm{Na}^{+}$influx and ATP depletion. Both the level of firing-induced $\mathrm{K}_{\mathrm{ATP}}$ opening and the steady-state level of $\mathrm{K}_{\mathrm{ATP}}$ opening were higher in the presence of the ketone body $\mathrm{R}-\beta$-hydroxybutyrate (R- $\beta \mathrm{HB})$, consistent with a previous study (Ma et al., 2007) showing that ketone bodies can alter neuronal electrical activity by opening $\mathrm{K}_{\mathrm{ATP}}$ channels.

\section{Materials and Methods}

Hippocampal slice preparation. Acute hippocampal slices $400 \mu \mathrm{m}$ thick were cut in the transverse plane from the brains of 12- to 16d-old male mice (C57BL/6; Charles River Laboratories) or Kir6.2 $2^{-1-}$ mice (in a C57BL/6 background) (Miki et al., 1998), using a vibrating tissue slicer (Vibratome). All procedures involving animals were approved by the Harvard Medical Area Standing Committee on Animals. Mice were anesthetized by halothane or isoflurane inhalation and decapitated into an ice-cold slurry containing the following (in mu): $87 \mathrm{NaCl}, 25 \mathrm{NaHCO}_{3}, 25$ D-glucose, 75 sucrose, $2.5 \mathrm{KCl}, 1.25 \mathrm{NaH}_{2} \mathrm{PO}_{4}, 0.5 \mathrm{CaCl}_{2}, 7$ $\mathrm{MgCl}_{2}$ (osmolarity $\sim 340 \mathrm{mmol} / \mathrm{kg} ; \mathrm{pH} 7.4$ with $\mathrm{NaOH}$ ).

Slices were incubated at $37^{\circ} \mathrm{C}$ for $20 \mathrm{~min}$ in the slicing solution and then for $40 \mathrm{~min}$ in recording solution, then stored at room temperature for $0-3 \mathrm{~h}$ before use. During recording, ACSF was delivered to the bath using a peristaltic pump at a flow rate of $\sim 0.9 \mathrm{ml} / \mathrm{min}$. All ACSF solutions for singlechannel recordings contained the following (in mM): $26 \mathrm{NaHCO}_{3}, 10$ D-glucose, $2.5 \mathrm{KCl}, 2 \mathrm{CaCl}_{2}, 1.25 \mathrm{NaH}_{2} \mathrm{PO}_{4}$, and $1 \mathrm{MgSO}_{4}$ (osmolarity $\sim 290 \mathrm{mmol} / \mathrm{kg} ; \mathrm{pH}$ 7.4). Standard single-channel ACSF also contained $120 \mathrm{~mm} \mathrm{NaCl}$; R- $\beta \mathrm{HB}$ solution contained $118 \mathrm{~mm} \mathrm{NaCl}, 2 \mathrm{~mm} \mathrm{NaOH}$, and $2 \mathrm{~mm}$ R- $\beta$-hydroxybutyric acid (Kanto Chemical). For whole-cell recordings, ACSF contained the following (in $\mathrm{mm}$ ): $119 \mathrm{NaCl}, 26$ $\mathrm{NaHCO}_{3}, 1 \mathrm{NaH}_{2} \mathrm{PO}_{4}, 10$ D-glucose, $2.5 \mathrm{KCl}, 2.5 \mathrm{CaCl}_{2}$, and $1.3 \mathrm{MgSO}_{4}$ (osmolarity $\sim 300 \mathrm{mmol} / \mathrm{kg} ; \mathrm{pH}$ 7.4). In addition, all recording solutions contained $100 \mu \mathrm{M}$ picrotoxin and $1 \mathrm{~mm}$ kynurenic acid to block fast synaptic transmission (all chemicals from Sigma-Aldrich unless otherwise noted). All bath solutions were bubbled continuously with $95 \% \mathrm{O}_{2}$ and $5 \% \mathrm{CO}_{2}$.

Electrophysiological recordings. Cell-attached patch recordings from individual DGNs identified under infrared differential interference contrast visual guidance were made in voltage-clamp mode following establishment of high-resistance (multi-G $\Omega$ ) seals. Data were collected with an Axopatch 200B integrating patch-clamp amplifier (MDS Analytical Technologies) in whole-cell mode $(\beta=1)$, sampled at $10-14 \mathrm{kHz}$, and filtered online at $1-2$ $\mathrm{kHz}$. Pipette potential was held at $0 \mathrm{mV}\left(\mathrm{V}_{\mathrm{m}}=\mathrm{V}_{\text {rest }}\right)$ for most experiments. All recordings were obtained at room temperature.

Patch pipettes were pulled from borosilicate glass capillary tubes (VWR Scientific) on a horizontal heated-filament puller (P-97; Sutter Instrument) and were wrapped about the shank close to the tip with stretched Parafilm to reduce capacitance. Pipettes with tip resistances of 3-6 $\mathrm{M} \Omega$ were used for cell-attached recordings and tip resistances of $2-4 \mathrm{M} \Omega$ were used for wholecell recordings. Pipette tips were not fire-polished.

For cell-attached recordings, the pipette solution contained the following (in mM): 140 potassium methanesulfonate (KMeS), 10 HEPES, 2
$\mathrm{CaCl}_{2}$, and 10 TEA-Cl, $2 \mathrm{CsCl}$, and 14 -aminopyridine (4-AP) (for blockade of non- $\mathrm{K}_{\mathrm{ATP}}$ potassium channels); osmolarity $\sim 310 \mathrm{mmol} / \mathrm{kg}$; $\mathrm{pH}$ to 7.4 with $\mathrm{KOH}$ ). For experiments (except those summarized in Fig. $1 B$ ), the patch pipette also contained additional peptide blockers of non- $\mathrm{K}_{\mathrm{ATP}}$ potassium channels: $100 \mathrm{~nm}$ charybdotoxin (in 0.001\% BSA; Alomone Labs) to block BK channels and $100 \mathrm{~nm}$ apamin to block SK channels (including $40 \mu \mathrm{M}$ acetic acid; Calbiochem).

DGNs were stimulated antidromically with a glass electrode placed in the hilus, proximal to the recording site. The stimulating electrode contained a HEPES-buffered ACSF and was driven by a D/A converter (Digidata 1321A; MDS Analytical Technologies) via an A360 stimulus isolation unit (WPI). Stimulation intensity was maintained at the minimum level required to reliably evoke spike activity. Stimulation was delivered in trains of five or 10 short $(80 \mu \mathrm{s})$ pulses at a frequency of $20 \mathrm{~Hz}$.

For paired experiments to assess glibenclamide effects, experiments were performed only on patches with relatively high initial channel activity. For this reason, the control segments of these paired experiments were not included in the averages of control activity that were used for unpaired comparisons (vs Kir6.2 $2^{-1-}$ animals or vs ketone body application), and the average peak $p_{\text {open }}$ was higher for these series of experiments. For the paired experiments, an approximately equal number of experiments were performed using vehicle (DMSO) without the experimental drug; the experiments were performed and analyzed by an investigator blind to the identity of the solution applied.

For whole-cell recordings, the pipette solution contained the following (in mM): $140 \mathrm{KMeS}, 10 \mathrm{NaCl}, 10 \mathrm{HEPES}, 1 \mathrm{MgCl}_{2}, 0.1$ EGTA (osmolarity $\sim 295 \mathrm{mmol} / \mathrm{kg}$; $\mathrm{pH} 7.4$ ), supplemented with $4 \mathrm{~mm}$ MgATP and $0.3 \mathrm{~mm}$ $\mathrm{Na}_{3} \mathrm{GTP}$. A voltage ramp protocol was used to measure input resistance: the holding potential was set at $-90 \mathrm{mV}$, followed by a $300 \mathrm{~ms}$ step to $-70 \mathrm{mV}$, then a $200 \mathrm{~ms}$ step back to $-90 \mathrm{mV}$ (for assessment of resting leak) and another $100 \mathrm{~ms}$ step to $-110 \mathrm{mV}$ to allow the membrane potential to settle before initiation of a $35 \mathrm{mV} / \mathrm{s}$ ramp from -110 to -20 
$\mathrm{mV}$, followed by a return to the $-90 \mathrm{mV}$ holding potential. The voltageramp protocol was applied every $5 \mathrm{~s}$ to provide a running assessment of whole-cell conductance.

For perforated patch recordings, the pipette solution contained the following (in mM): $140 \mathrm{KCl}, 10 \mathrm{NaCl}, 10 \mathrm{HEPES}, 1 \mathrm{MgCl}_{2}$ (pH 7.3). The pipette solution also contained 50-100 $\mu \mathrm{g} / \mathrm{ml}$ gramicidin D (Sigma). Before experiments, fresh gramicidin stock solution ( $5 \mathrm{mg} / \mathrm{ml}$ in DMSO) was prepared and diluted in the pipette solution. Additionally, Alexa 488 (10 $\mu \mathrm{M}$; Invitrogen) was added to the pipette solution to monitor the integrity of the perforated cell membrane. The pipette tip was filled with gramicidin-free solution and then back-filled with the gramicidincontaining solution. Perforation generally occurred within $30 \mathrm{~min}$ of forming a seal. Current-clamp recordings were performed on cells held near $-60 \mathrm{mV}$, which allowed for consistent observation of slow afterhyperpolarizations (Podlogar and Dietrich, 2006). Trains of action potentials were triggered by five current pulses ( $5 \mathrm{~ms}, 100 \mathrm{pA})$ at $20 \mathrm{~Hz}$.

Drugs and solutions. All drugs used were bath-applied in ACSF. Glibenclamide was diluted from a $1 \mathrm{~mm}$ stock solution in DMSO down to 100 $\mathrm{nM}$ in ACSF. DMSO as a vehicle control for glibenclamide was added to ACSF at $0.01 \%$. NN414 was diluted from a $250 \mathrm{~mm}$ stock in DMSO to a concentration of 5-10 $\mu \mathrm{M}$ in ACSF. Strophanthidin was made as a $0.5 \mathrm{M}$ stock in DMSO diluted down to $500 \mu \mathrm{M}$ in ACSF. DMSO as a vehicle control for strophanthidin was added to ACSF at 0.1\%. NN414 was a gift from Novo Nordisk.

Data analysis. Most experiments were performed and analyzed by an experimenter blind to genotype or treatment condition. Data were analyzed offline with Clampfit, Microsoft Excel (Microsoft), MATLAB (Mathworks), and Microcal Origin (OriginLab).

In-house software written in MATLAB was used for primary offline analysis of raw data. For analysis, data were filtered to $500 \mathrm{~Hz}$. For binary idealization of channel openings, stimulus artifacts and capacitive action currents were blanked from the filtered data traces, which were then subjected to a baseline subtraction where the mean current level at each time point was subtracted from all traces. The mean current for subtraction was calculated after exclusion of traces in the top quartile (for data with few channel openings) or in the top $67 \%$ (for data with large numbers of peristimulus openings).

Open and closed levels for channel activity were determined from an all-points histogram of the filtered data, and channel openings were detected using a 50\% threshold criterion applied to filtered $(500 \mathrm{~Hz})$ raw data. Raw datasets featuring excessive baseline shift, sufficient high- or low-frequency noise to preclude effective idealization of channel openings, insufficient entrainment of spikes to stimulus, or too few data traces $(<36 ; 3$ min of recording) were generally discarded without idealization or further analysis. In the case of data recorded in the absence of stimulation, either for comparison with records where spiking was stimulated, or for channel identification with $\mathrm{K}_{\mathrm{ATP}}$ opening drugs, trials containing $<36$ traces were occasionally included for analysis.

The amplitude of the slow afterhyperpolarization (sAHP) was calculated as the minimum of a $250 \mathrm{~ms}$ moving average voltage, minus the median voltage of the baseline. The post-sAHP spike latency was measured as the first time point to exceed $-10 \mathrm{mV}$ after the last evoked action potential. For each experiment, we calculated the $80 \%$ trimmed mean (excluding the high and low 10\%), then calculated mean and SEM across experiments. Significance by a nonparametric (Mann-Whitney) test was $<0.05$ for both latency and sAHP voltage.

\section{Results}

We performed cell-attached single channel recordings on DGNs using a high- $\left[\mathrm{K}^{+}\right]$pipette solution with a mixture of ionic channel blockers (TEA, 4-AP, and $\mathrm{Cs}^{+}$) designed to isolate $\mathrm{K}_{\mathrm{ATP}}$ channels (see Materials and Methods, above), as previously done by Pelletier et al. (2000). With this solution, we observed channels in nine of 14 patches $(\sim 64 \%)$ that had characteristics of DGN K $\mathrm{ATP}_{\mathrm{ATP}}$ channels (Fig. 1). Single-channel currents reversed at a pipette potential close to the cell resting potential $(\sim-80 \mathrm{mV}$, corresponding to a transmembrane potential of $\sim 0 \mathrm{mV}$ ), as expected for a potassium-selective channel with $140 \mathrm{~mm}$ extracellular $\mathrm{K}^{+}$.
The slope conductance of $\sim 25 \mathrm{pS}$ was smaller than usually reported for Kir6.2-containing $\mathrm{K}_{\mathrm{ATP}}$ channels (in the range of 50-80 pS) (Cook and Hales, 1984; Inagaki et al., 1995; Babenko et al., 1998) but very close to that reported for endogenous $K_{\text {ATP }}$ channels recorded in rat DGNs (Pelletier et al., 2000). The singlechannel current-voltage relationship showed little rectification up to $\mathrm{V}_{\text {rest }}+50 \mathrm{mV}$ (Fig. $1 \mathrm{~B}$ ), characteristic of the Kir6.x class of inward rectifier channels (Baukrowitz et al., 1999). Also, the channels recorded under these conditions showed increased $p_{\text {open }}$ in the presence of the SUR1-specific $\mathrm{K}_{\mathrm{ATP}}$-opening drug NN414 (5 $\mu \mathrm{M})$ (Fig. 1C) (Dabrowski et al., 2003). For all subsequent experiments, the patch pipette also contained additional peptide blockers of non- $\mathrm{K}_{\mathrm{ATP}}$ potassium channels: $100 \mathrm{nM}$ charybdotoxin (in $0.001 \%$ BSA; Alomone Labs) to block BK channels and $100 \mathrm{nM}$ apamin to block SK channels (including $40 \mu \mathrm{M}$ acetic acid; Calbiochem).

\section{Action potential firing elevates $\mathrm{K}_{\mathrm{ATP}}$ channel open probability in cell-attached patches}

We tested whether the firing of DGNs could bias $\mathrm{K}_{\mathrm{ATP}}$ channels toward opening, perhaps because of the increased metabolic demand. We drove DGNs to fire using antidromic stimulation from the hilus, as this permitted us to record under conditions of synaptic blockade, thus further decreasing the already low rate of spontaneous DGN firing and eliminating some complications that might arise from synaptic transmission.

We stimulated $20 \mathrm{~Hz}$ bursts of five action potentials every $5 \mathrm{~s}$ and recorded dozens to hundreds of consecutive $5 \mathrm{~s}$ sweeps of voltage-clamped current from each cell. The cell-attached recordings simultaneously recorded openings and closings of individual $\mathrm{K}_{\mathrm{ATP}}$ channels along with capacitive action currents fired in response to stimulation (Fig. $2 \mathrm{~A}$ ).

Time-course histograms of the average $K_{\mathrm{ATP}}$ channel open probability, obtained from analysis of a full set of sweeps, typically showed a marked elevation in channel $p_{\text {open }}$ during and immediately following the stimulus interval (Fig. $2 B$ ). On average, across all experiments recorded in ACSF with this stimulation paradigm, the elevation in channel $p_{\text {open }}$ lasted the duration of the stimulus period and attained a mean value of $1.09 \pm 0.32 \%$ $(n=35)$ for the entire intrastimulus interval; this transient increase in $p_{\text {open }}$ persisted for $\sim 0.5-1$ s beyond the end of the stimulation period (Fig. 2C). This increase in channel activity reached a level more than double that of the basal $p_{\text {open }}$ exhibited during the nonspiking quiescent period (taken as the last second of the $5 \mathrm{~s}$ recording epoch), where the open probability typically dropped to a very low level: $<0.1 \%$ in some cases, and to $0.46 \pm$ $0.17 \%$ on average.

Qualitatively, this observation suggests that $\mathrm{K}_{\mathrm{ATP}}$ channels open preferentially in response to stimulated firing in DGNs. The effect depended on action potential firing; when the stimulus was turned off, the activation profile of the channels in the ensemble averages of the zero-spike condition showed no elevation (Fig. $2 B, C)$. For the unstimulated condition, the peak open probability during the equivalent time period where spikes were stimulated to fire for the five-stimulus condition was $0.13 \pm 0.03 \%$, compared with a mean basal $p_{\text {open }}$ during the last second of the recording period of $0.14 \pm 0.04 \%(n=13)$. While there was no significant difference between the basal open probabilities over the last second of the recording epoch for the two conditions ( $5 \mathrm{vs}$ 0 stimuli; $p=0.24$, Mann-Whitney $U$ test), the spike-elevated peak $p_{\text {open }}$ recorded with five stimuli delivered was significantly greater than that recorded during the equivalent time period in the absence of stimulation $(p<0.01)$. Comparable effects were 

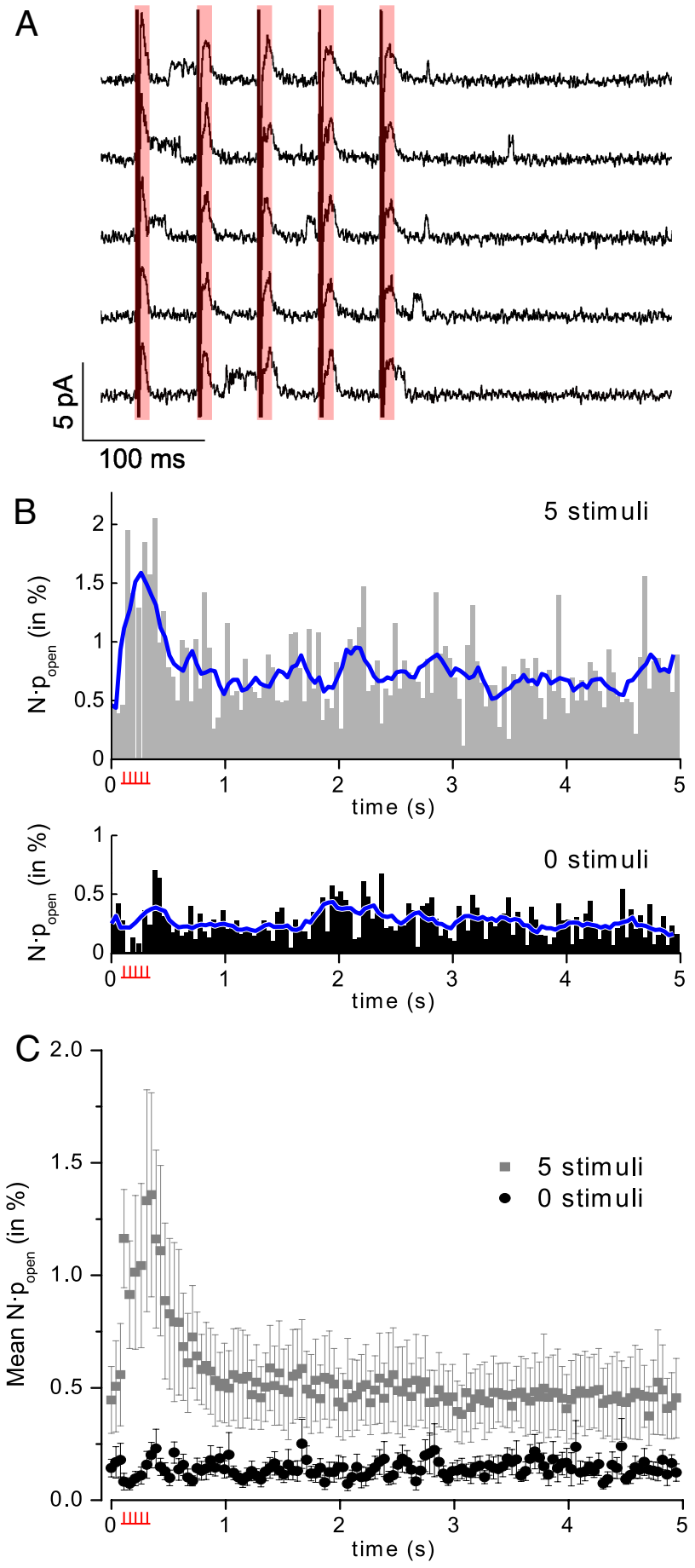

Figure 2. Stimulated spike activity increases channel $p_{\text {open }}$ A $\boldsymbol{A}$, Five examples of cell-attached records from a DGN with five stimuli delivered at $20 \mathrm{~Hz}$, showing channel openings just for the period during and after action potential stimulation. The red shading indicates the period of stimulus artifact and action potential. $\boldsymbol{B}$, Top, Histogram of channel activity (ensemble average open probability) over all traces from a representative five-stimulus experiment. The blue line shows a $320 \mathrm{~ms}$ moving average value. A prominent elevation in channel $p_{\text {open }}$ can be observed during and after the stimulus period (indicated by the stimulus icon beneath the time axis). Bottom, A second histogram for the same patch for traces during which no stimuli were applied. Channel activity for all experiments is reported as $\mathrm{N} \cdot \mathrm{p}_{\text {open }}$ to acknowledge the possibility that more than one channel is active in a given patch. C, Summary for all trials where cells were stimulated to fire five spikes at $20 \mathrm{~Hz}$ versus all trials where no stimulus was delivered. The peak stimulus-period $p_{\text {open }}$ for five stimuli are significantly different from those for the equivalent time period in trials where no spikes were stimulated to fire $\left(p<0.01\right.$; Mann-Whitney $U$ test). Gray squares, Mean N $p_{\text {open }}$ for all five-stimulus trials $(n=35)$; black circles, mean $N \cdot p_{\text {open }}$ for all trials conducted without stimulation $(n=13)$. Data points are presented as mean channel $p_{\text {open }} \pm$ SEM. seen with 10 stimuli, also administered at $20 \mathrm{~Hz}$ : mean $p_{\text {open }}$ was $0.85 \pm 0.15 \%$ during the stimulus period and $0.38 \pm 0.09 \%$ at steady-state $(n=40 ; p<0.001)$. The decay of the $p_{\text {open }}$ back to a steady-state level after the end of the stimulus period was fitted with a single exponential, giving time constants of $\tau=0.32 \pm$ $0.02 \mathrm{~s}$ for five spikes and $\tau=0.46 \pm 0.06 \mathrm{~s}$ for 10 spikes.

\section{Confirmation of $\mathrm{K}_{\mathrm{ATP}}$ channel identity}

Although our pipette recording solution contained a mixture of channel blockers (TEA, 4-aminopyridine, $\mathrm{CsCl}$, charybdotoxin, and apamin) designed to isolate $\mathrm{K}_{\mathrm{ATP}}$ channels (see Materials and Methods, above), we used both pharmacological and genetic tests to confirm this identification. To pharmacologically identify $\mathrm{K}_{\mathrm{ATP}}$ channels, we recorded stimulus-dependent channel activity first in ACSF and then after 15 min perfusion with $100 \mathrm{nM}$ glibenclamide, a potent blocker of $\mathrm{K}_{\mathrm{ATP}}$ channels.

Glibenclamide substantially reduced the peak $p_{\text {open }}$ during the stimulus period (Fig. 3A). To analyze these paired experiments, we plotted $\Delta p_{\text {open }}$ (glibenclamide - ACSF) as a function of the initial $p_{\text {open }}$ in ACSF, using a peak-weighted average measurement of $p_{\text {open }}$ (explained in Fig. 3's legend). The expected result is a line with a negative slope corresponding to the fractional reduction in single-channel activity (Fig. 3B). For peak channelopening responses, the fitted slope corresponded to an $81 \%$ $( \pm 2 \%)$ fractional reduction in activity with glibenclamide (significantly different from zero by $F$-distribution test; $p<0.01$ ). For measurement of channel opening over the entire trace, the fitted slope corresponded to an $87 \%( \pm 2 \%)$ fractional reduction in channel current with glibenclamide $(p<0.01)$. In interleaved control experiments (performed and analyzed blind to the condition) where the $0.01 \%$ DMSO vehicle without glibenclamide was washed in, there was a slight downward trend for both the peak and the full-trace $p_{\text {open }}$ (Fig. $3 B$ ), but any apparent DMSO effect was much smaller than that for glibenclamide. Also, there was no overlap between the confidence bands for the fitted slopes of the drug and vehicle control conditions (Fig. $3 B$ ), indicating that the effect of glibenclamide treatment is significantly greater than the effect of DMSO treatment or any rundown that may have occurred.

As a genetic test of channel identity, we used brain slices from knock-out mice containing a disrupted Kir6.2 gene (Miki et al., 1998). These experiments showed a much smaller open probability and stimulus-induced elevation than seen in wild-type animals (Fig. 3C). There was still a small amount of channel activity in the knock-out animals, which may indicate that our recording pipette mixture does not completely block all other $\mathrm{K}^{+}$channel types, or that there are some $\mathrm{K}_{\mathrm{ATP}}$ channels formed by the alternative pore-forming Kir6.1 subunits (also capable of forming $\mathrm{K}_{\mathrm{ATP}}$ channels).

Nevertheless, comparison of the results from the two genotypes studied showed that the prominent activity-dependent increase in channel $p_{\text {open }}$ seen in wild-type animals was largely attenuated or absent during the stimulus period in Kir6.2 ${ }^{-1-}$ knock-out animals. Over half $(6$ of $11 ; 55 \%)$ of the trials from knock-out animals showed little to no channel activity $(<0.05 \%$ steady-state basal open probability) compared with only eight of $35(23 \%)$ trials from wild-type animals exhibiting such low levels of activity, as recorded and analyzed under the same conditions (Fig. 3C). Of the five trials from knock-outs that did show some appreciable level of channel activity, only one exhibited any apparent stimulus-period elevation in $p_{\text {open }}$ at all. Overall, the peak open probability during the stimulus period was significantly lower in knock-out animals than in wild-type ( $p<0.05$, Mann- 

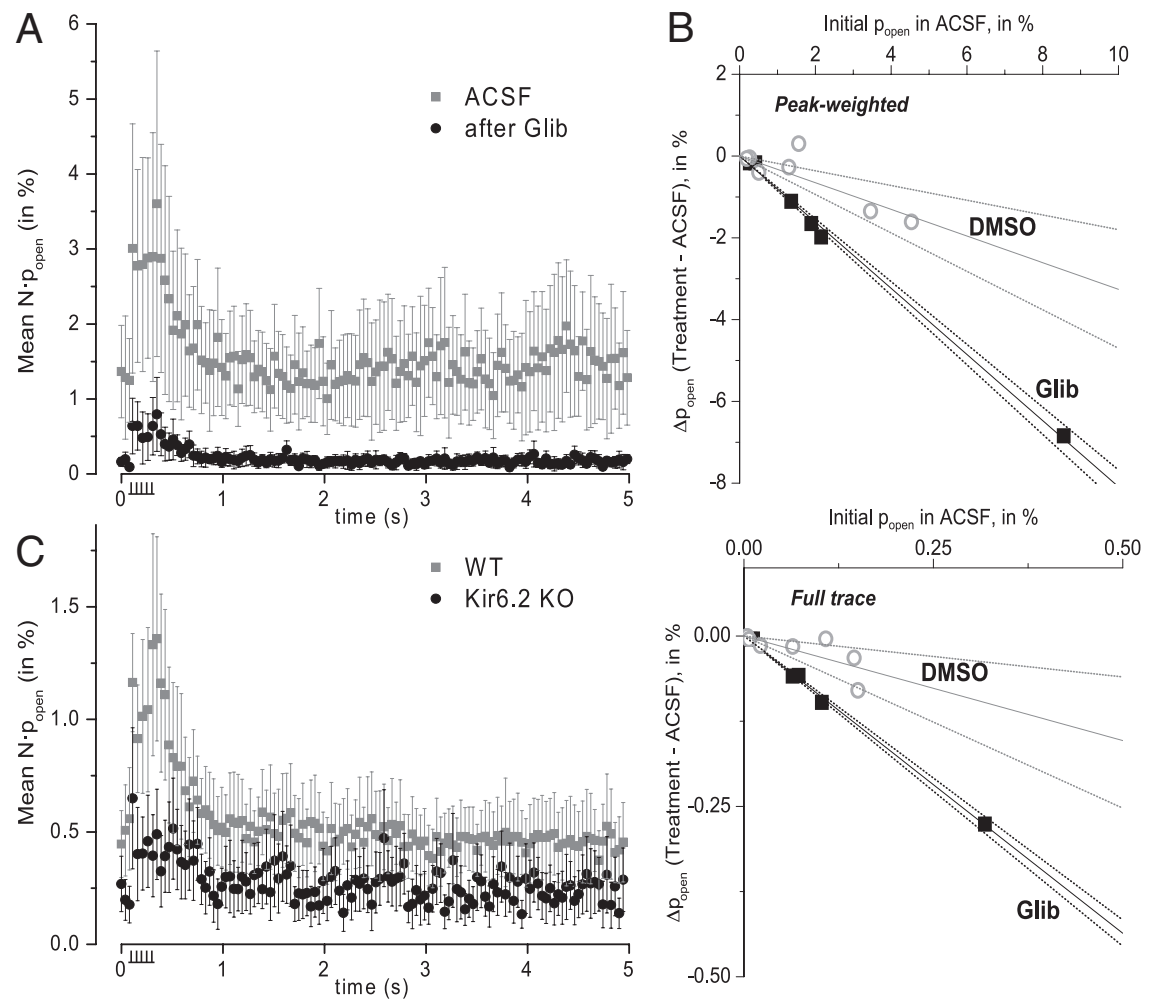

Figure 3. Both the firing-induced and basal channel openings are mainly $\mathrm{K}_{\mathrm{ATP}}$ channels. $\boldsymbol{A}$, Average effect of glibenclamide wash-in on channel open probability after recording of baseline activity in ACSF. The $K_{\text {ATP }}$ blocking drug glibenclamide (100 nM) attenuates the spike-elevated opening of channels compared with paired five-stimulus trials recorded in ACSF alone. Mean \pm SEM; $n=6$. $\boldsymbol{B}$, Estimate of the fractional blockade by glibenclamide. $\Delta p_{\text {open }}$ (final - initial) is plotted against the initial $p_{\text {open }}$ (in ACSF), with each symbol representing a separate experiment with glibenclamide (black squares) or DMSO (gray circles) wash-in. Linear fits through the origin, for each dataset, represent a fixed fractional reduction in current produced by the blocker. The two graphs use different time samples: full-trace effects (bottom) simply used the full-trace average $p_{\text {open, }}$ while peak-weighted effects (top) were weighted with a function that was constant during the stimulus interval and decayed with a time constant of $0.3 \mathrm{~s}$ thereafter. Dotted lines mark the $95 \%$ confidence limits for the linear fits. For glibenclamide, the fitted slopes were (peak) $-0.81 \pm 0.02$ and (full) $-0.87 \pm 0.02$, consistent with $\sim 80-90 \%$ inhibition. For DMSO, the fitted slopes were (peak) $-0.33 \pm 0.06$ and (full) $-0.31 \pm 0.08(n=7)$. C, Channel activity is reduced in DGNs from Kir6.2 knock-out mice. Summary for experiments with five-stimuli in wild-type animals (gray symbols, mean $\pm \mathrm{SEM}, n=35$ ), and Kir6.2 ${ }^{-/-}$(black symbols, mean $\pm \mathrm{SEM}, n=11$ ). Most experiments were performed and analyzed blind to genotype.

Whitney $U$ test). The absence of a spike-induced elevation in the majority of slices from Kir6.2 knock-out animals again suggests that the activity observed in wild-type animals is largely due to $\mathrm{K}_{\mathrm{ATP}}$ channels.

\section{The $\mathrm{Na}^{+}-\mathrm{K}^{+}$pump blocker strophanthidin attenuates the spike-dependent effect}

$\mathrm{K}_{\text {ATP }}$ channel opening is primarily controlled by the intracellular ATP and ADP concentrations. The main metabolic consequence of action potential firing arises from the restoration of ion channel gradients by ATP-dependent pumps, principally the $\mathrm{Na}^{+}-\mathrm{K}^{+}$ATPase. To test for a role of the $\mathrm{Na}^{+}-\mathrm{K}^{+}$ATPase in the activity-induced opening of $\mathrm{K}_{\mathrm{ATP}}$ channels, we performed a set of experiments in which we bath-applied the pump inhibitor strophanthidin following a control recording in ACSF. In experiments using 10 stimuli, bath application of strophanthidin often resulted in a marked decrement in both stimulus-elevated and steady-state $p_{\text {open }}$ compared with paired ACSF controls (Fig. 4). Control application of DMSO in these experiments resulted in a higher average $p_{\text {open }}$ than that recorded in ACSF-only conditions.

There was a clear effect of strophanthidin in these experiments, decreasing $p_{\text {open }}$ during both the stimulus-elevated peak (71 $\pm 15 \%$ fractional reduction in peak-weighted open probabil- ity, $p<0.001, F$-distribution test) and over the course of the full trace $(75 \pm 14 \%$ fractional reduction in open probability for the whole trace, $p<0.001, F$-distribution test) (Fig. $4 B$ ). In several cases, strophanthidin eliminated the spike-dependent increase in channel $p_{\text {open }}$ completely (Fig. $4 A$ ). In control experiments where the $0.1 \%$ DMSO vehicle alone was washed in, comparison of $\Delta p_{\text {open }}$ (vehicle - ACSF) versus ACSF $p_{\text {open }}$ showed an upward trend for both the peak and the full-trace $p_{\text {open }}$. Again, as in the case of the glibenclamide-DMSO comparisons, there was no overlap between the confidence bands for the fitted slopes of the drug and vehicle control conditions (Fig. 4C).

We also analyzed these experiments by categorizing the results of individual experiments as increased, decreased, or no change, using an arbitrary threshold of $\pm 0.25 \%$ change in the peak-weighted $p_{\text {open }}$. By this criterion, strophanthidin reduced the stimulus-evoked increase in channel $p_{\text {open }}$ in six of 13 experiments, produced no change in six, and produced an increase in one. By the same criterion, DMSO produced a decrease in one of 11 experiments, no change in four, and an increase in six. A $\chi^{2}$ analysis of the contingency table confirmed a significant effect of strophanthidin versus vehicle controls $(p<0.01)$.

\section{Ketone bodies increase both} steady-state and stimulus-elevated $p_{\text {open }}$ The strophanthidin experiments show that the metabolic load produced even by a short burst of action potentials could result in the opening of $\mathrm{K}_{\mathrm{ATP}}$ channels. This result led us to investigate additional ways to manipulate $\mathrm{K}_{\mathrm{ATP}}$ channel activity by altering metabolic conditions. It has been shown that $\mathrm{K}_{\mathrm{ATP}}$ channels in DGNs can be opened under conditions of joint hypoxia and hypoglycemia (Pelletier et al., 2000), which underscores the metabolic sensitivity of these channels. In previous studies of a different population of neurons, the GABAergic neurons of substantia nigra pars reticulata $(\mathrm{SNr})$, we found that ketone bodies, which circulate at high levels in the blood of patients and animals on an anticonvulsant ketogenic diet, can slow spontaneous neuronal firing by opening $\mathrm{K}_{\mathrm{ATP}}$ channels (Ma et al., 2007). We therefore looked for a similar effect on $\mathrm{K}_{\mathrm{ATP}}$ channels in DGNs.

Using the five stimulus paradigm, we recorded single-channel activity from DGNs in wild-type slices preincubated in ACSF containing $10 \mathrm{~mm}$ glucose (as before) and supplemented with 2 $\mathrm{mM}$ of the ketone body $\mathrm{R}-\beta \mathrm{HB}$. We found that $2 \mathrm{~mm} \mathrm{R}-\beta \mathrm{HB}$ increased not only the steady-state open probability of the channel, but also the stimulus-elevated $p_{\text {open }}$ (Fig. 5). For the experiments with $\mathrm{R}-\beta \mathrm{HB}$, the mean peak $p_{\text {open }}$ during the stimulus interval was nearly threefold higher than that recorded in ACSF $(3.14 \pm 0.90 \%, n=8$ in $\mathrm{R}-\beta \mathrm{HB}$, vs $1.09 \pm 0.32 \%, n=35$ in ACSF; different with $p<0.05$ by Mann-Whitney $U$ test). The mean basal $p_{\text {open }}$ in $\mathrm{R}-\beta \mathrm{HB}$ was also increased over that seen in 
$\operatorname{ACSF}(1.71 \pm 0.64 \%$ in $\mathrm{R}-\beta \mathrm{HB}$ vs $0.46 \pm$ $0.17 \%$ in ACSF; different with $p<0.01$ ). The decay time constant after stimulation was $0.30 \pm 0.05 \mathrm{~s}$, very similar to that determined for ACSF alone $(\tau=0.32 \pm$ $0.02 \mathrm{~s})$.

$K_{\text {ATP }}$ channels contribute to the slow afterhyperpolarization following action potential firing

We tested whether the elevated $K_{\text {ATP }}$ channel open probability after action potential bursts produced a hyperpolarization of the membrane potential. To avoid disturbing intracellular ATP levels, we used the gramicidin perforated patch technique (Kyrozis and Reichling, 1995) to record the membrane potential after evoking spike bursts. After perforation, cells were held in current clamp near -60 $\mathrm{mV}$ and, following a $20 \mathrm{~Hz}$ train of five action potentials evoked by brief current pulses, we observed an sAHP (Fig. 6). $\mathrm{K}_{\mathrm{ATP}}$ channels contribute to this sAHP, as application of $100 \mathrm{nM}$ glibenclamide reduced the amplitude of the SAHP (Fig. 6). The mean sAHP was $-8.8 \pm 1.1 \mathrm{mV}$, and was significantly smaller in the presence of glibenclamide, $-5.7 \pm 0.7 \mathrm{mV}(n=5, p<$ $0.05)$. We also observed that spontaneous action potential firing stopped during the sAHP and resumed only after the resting potential returned to the baseline level. Glibenclamide shortened the latency to resumption of firing after the evoked train of action potentials and the AHP from a mean latency of $6.5 \pm 0.7 \mathrm{~s}$ to $4.1 \pm 0.6 \mathrm{~s}(n=$ $5, p<0.05)$.

\section{Discussion}

Spike activity in granule cells opens up $\mathrm{K}_{\mathrm{ATP}}$ channels via $\mathrm{Na}^{+}-\mathrm{K}^{+}$pump activity

In our recordings of single $\mathrm{K}_{\mathrm{ATP}}$ channels in membrane patches of hippocampal dentate granule neurons, we have identified a link between spike-burst activity in the DGN and the opening of these metabolically sensitive channels. With a brief burst of action potentials, it was possible to systematically increase $\mathrm{K}_{\mathrm{ATP}}$ channel open probability above the usually very low levels of activity that these channels exhibit in the resting state. This spikedependent increase in $\mathrm{K}_{\mathrm{ATP}}$ channel $p_{\text {open }}$ was attenuated or abolished in the presence of strophanthidin, a blocker of the $\mathrm{Na}^{+}-\mathrm{K}^{+}$ ATPase. This result suggests that an increase in cellular firing activity imposes a metabolic stress on the cell that, in the absence of pump blockade, is sufficient to open $\mathrm{K}_{\mathrm{ATP}}$ channels above their low steady-state resting levels, most likely via ATP depletion (Kabakov, 1998).

We included a number of channel blockers in our experiments to eliminate most $\mathrm{K}^{+}$channels other than $\mathrm{K}_{\mathrm{ATP}}$ channels, including the ionic blockers 4-AP, cesium, and TEA (to broadly block Kv and Kir channels), as well as two peptide blockers, charybdotoxin (to block BK channels) and apamin (to block SK channels). The channel activity observed under these conditions was blocked by glibenclamide and nearly eliminated in knockout mice lacking the major pore-forming subunit of neuronal
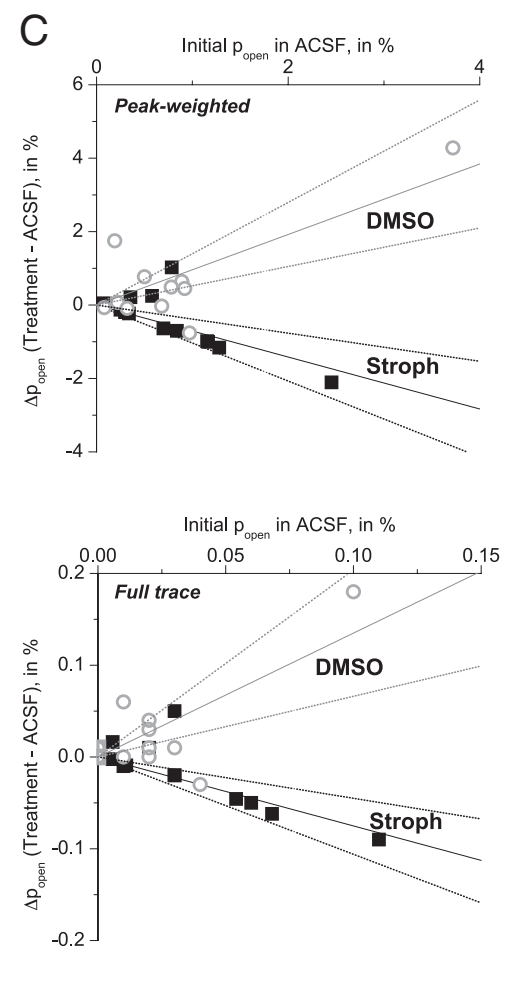

- ACSF

- after strophanthidin

\section{ACSF} .

Figure 4. The $\mathrm{Na}^{+}-\mathrm{K}^{+}$pump blocker strophanthidin blocks both the firing-induced and basal channel opening. $A, B$, Channel activity was recorded first in ACSF, then in strophanthidin; histograms are shown for a representative experiment $(\boldsymbol{A})$ and for the

$\mathrm{K}_{\mathrm{ATP}}$ channels, Kir6.2 (Fig. 3). However, some small activity did remain. We cannot rule out some contribution in our experiments from apamin-insensitive SK channels, or from Kir6.1containing $\mathrm{K}_{\mathrm{ATP}}$ channels, but it does appear that the majority of the stimulus-evoked channel opening that we observed can be accounted for by glibenclamide-sensitive, Kir6.2-containing $\mathrm{K}_{\text {ATP }}$ channels.

We also found that action potential bursts evoked in individual DGNs recorded using a perforated patch approach produced an sAHP that was sensitive to glibenclamide. Our finding from our cell-attached recordings that $\mathrm{K}_{\mathrm{ATP}}$ channel open probability is elevated after bursts of action potentials is consistent with a role of $\mathrm{K}_{\text {ATP }}$ channels in the sAHP. The long duration of the sAHP would require a contribution not only from the transient elevation in open probability induced by firing, but also from the chronic elevation apparent in the steady-state open probability [which was also dependent on regular stimulation, as seen from its disappearance when stimulation was turned off (Fig. 2)]. $\mathrm{K}_{\mathrm{ATP}}$ channels account for only a fraction of the sAHP; another component of the sAHP in hippocampal neurons has been attributed to KCNQ channels (Tzingounis and Nicoll, 2008). Loss of KCNQ channels also eliminates only a portion of the sAHP. Our finding suggests that $\mathrm{K}_{\mathrm{ATP}}$ channels may contribute the sAHP in DGNs and possibly function to reduce excitability in conditions of elevated neuronal firing.

\section{The likely size of these $K_{\text {ATP }}$ effects at a whole-cell level}

To gain an additional sense for how this spike-induced opening of $\mathrm{K}_{\mathrm{ATP}}$ channels might functionally affect overall cellular excitability, we can estimate the fractional change in input conduc- 
A

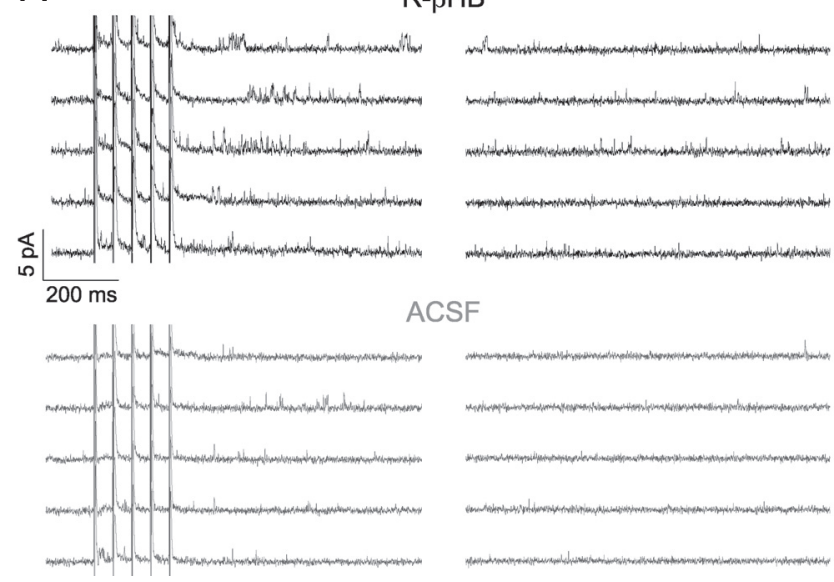

B

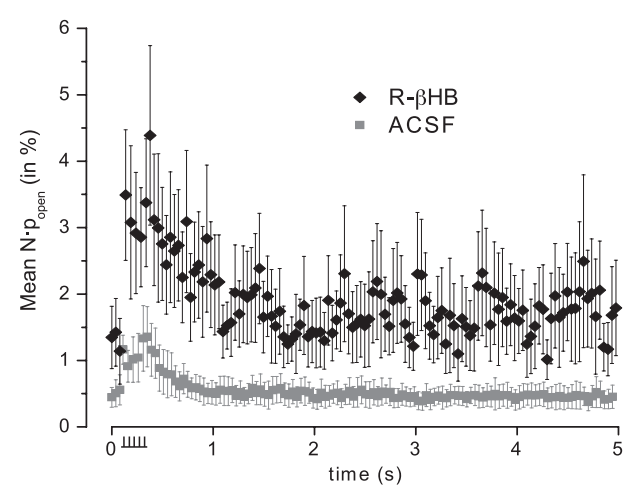

Figure 5. Channel open probability is elevated with the ketone body $R-\beta$-hydroxybutyrate. $A$, Top, Set of five current traces recorded in ACSF supplemented with $2 \mathrm{~mm} R-\beta H B$. Bottom, Set of five current traces recorded in ACSF alone. Left, First second of recording period. Right, Last second. B, Summary of all experiments in R- $\beta$ HB (black diamonds; $n=8$ ) versus all in ACSF (gray squares; $n=35$ ). Note that the $y$-axis is on a larger scale than in previous sets of summary data.
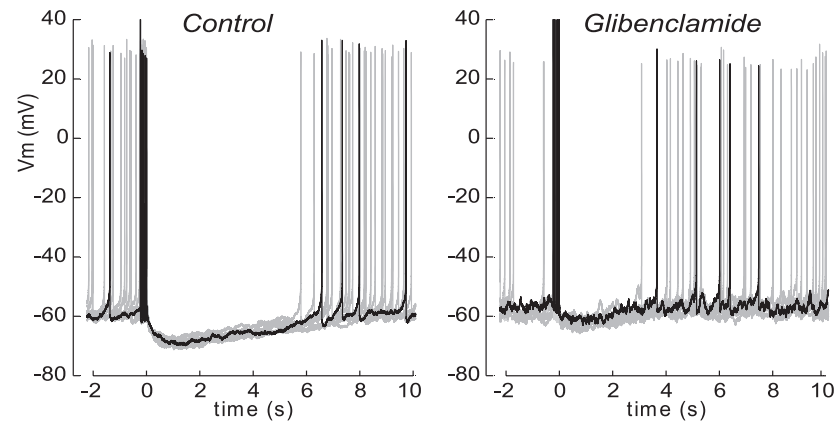

Figure 6. A glibenclamide-sensitive, long, slow AHP following a burst of evoked action potentials. Representative perforated patch voltage recordings from DGNs, with a burst of five action potentials evoked by five brief current pulses just before the indicated $t=0$. A total of eight traces are overlaid, with a single trace shown in black. In recordings with glibenclamide, AHPs were smaller ( $\Delta \mathrm{V}=-5.7 \pm 0.7 \mathrm{mV}$ vs $-8.8 \pm 1.1 \mathrm{mV}$ for control; $n=5, p<0.05$ ) and spontaneous action potential firing resumed after a shorter latency $(4.1 \pm 0.6 \mathrm{~s}$ vs $6.5 \pm$ 0.7 s for control; $n=5, p<0.05$ ).

tance. In whole-cell recordings with a high-ATP pipette solution, we found that the $\mathrm{K}_{\mathrm{ATP}}$ channel opener NN414 produced a whole-cell $\mathrm{K}_{\mathrm{ATP}}$ conductance of $\sim 0.8 \mathrm{nS}(n=2)$. In cell-attached single-channel recordings, we observed a mean $p_{\text {open }}$ in NN414 of $4.7 \pm 1.7 \%$, compared with a resting $p_{\text {open }}$ (in ACSF alone) of $0.19 \pm 0.02 \%$. The peak $p_{\text {open }}$ responses in our five-stimulus experiments of $\sim 1.1 \%$ - approximately one-fifth of the NN414-induced $p_{\text {open }}$ - may thus correspond to a total conductance on the order of $\sim 160 \mathrm{pS}$, which would represent a substantial $(\sim 30 \%)$ increase over the resting conductance of $\sim 400-500 \mathrm{pS}$ observed at this age (and in our own whole-cell experiments). A similar calculation applied to the R- $\beta \mathrm{HB}$ treatment yields an even more substantial $(\sim 100 \%)$ increase in conductance.

The intrinsic membrane properties (Liu et al., 2000) and synaptic plasticity (Schmidt-Hieber et al., 2004) of young or newly generated dentate granule cells change significantly as they age. A key difference between cells of different ages is their input resistance: $\sim 2.5 \mathrm{G} \Omega$ for young neurons (corresponding to $0.4 \mathrm{nS}$ conductance) and $\sim 250 \mathrm{M} \Omega$ for older neurons (corresponding to $4 \mathrm{nS}$ conductance). This difference suggests that the potential effects of a spike-induced elevation of channel $p_{\text {open }}$ may be more pronounced in younger animals.
Could $\mathrm{K}_{\mathrm{ATP}}$ channel opening represent one mechanism for tempering seizure propagation in the temporal lobe?

The hippocampal formation is one of the most widely studied regions of the brain where $\mathrm{K}_{\mathrm{ATP}}$ channels are known to be broadly expressed. To date, however, no clear understanding has emerged of what role these channels might serve in the hippocampus beyond neuroprotection during ischemia or ischemia-induced seizures (Krnjević and Ben-Ari, 1989; Ben-Ari et al., 1990; Yamada et al., 2001). We have shown that externally driven spiking in hippocampal DGNs, imposed at relatively high rates, leads to the sustained opening of $\mathrm{K}_{\mathrm{ATP}}$ channels in these cells.

This result agrees with and extends studies of $\mathrm{K}_{\mathrm{ATP}}$ channels in rat respiratory neurons (Haller et al., 2001). In the respiratory neurons, which have a spontaneous population rhythm, the clearest change in $p_{\text {open }}$ was the closure of $\mathrm{K}_{\mathrm{ATP}}$ channels seen immediately before burst cycle; opening of channels occurred fairly gradually after each burst. The slow response may reflect the asynchrony of action potential firing in different respiratory cells, so that the increase in $\mathrm{K}_{\mathrm{ATP}}$ channel opening is dispersed in time from burst to burst. In our preparation, with precisely controlled timing, we observe $\mathrm{K}_{\mathrm{ATP}}$ channels opening up promptly following stimulated spiking - an occurrence that could serve to temper any further excitation in the wake of an unusually high-frequency spike burst.

In the basic trisynaptic hippocampal circuit, DGNs are the first point of input from the entorhinal cortex into the hippocampus. This privileged positioning of DGNs in the circuit may permit them to act as a seizure gate in temporal lobe epilepsy (Heinemann et al., 1992; Lothman et al., 1992; Coulter and Carlson, 2007). While DGNs are typically reported to fire at very low rates (Jung and McNaughton, 1993), the spike frequencies we delivered are not out of the range of possibility for these cells. Indeed, these cells have been reported to fire at frequencies of up to $25 \mathrm{~Hz}$ or more at the onset of seizures in rats during pilocarpine-induced status epilepticus (Bower and Buckmaster, 2008). Therefore, our chosen rates of stimulation are likely to be visited during epileptic-like states.

The opening of $\mathrm{K}_{\mathrm{ATP}}$ channels in DGNs could serve to limit the passage of excitation to more distal parts of the circuit in cases where the firing rate of these gating neurons is vastly increased by excessive excitatory synaptic input, such as might occur during seizure episodes. Indeed, it has been demonstrated in paired re- 
cordings that single spikes in DGNs generally do not induce spiking in CA3 pyramidal cells, but that high-frequency trains of DGN spikes can do so consistently (Henze et al., 2002). This result suggests that mechanisms for tempering high-frequency excitation in DGNs can have significant effects on downstream target neurons.

We also found that applying ketone bodies to hippocampal slices augments both the basal channel $p_{\text {open }}$ and the stimuluselevated open probability above that observed in ACSF alone. This result supports the role of $\mathrm{K}_{\mathrm{ATP}}$ channels as a link between metabolism and neuronal excitability in central neurons, and supplements our earlier findings that ketogenic diet metabolites can slow the spontaneous firing of neurons in the $\mathrm{SNr}$ via opening of $\mathrm{K}_{\mathrm{ATP}}$ channels (Ma et al., 2007). Like the dentate gyrus, the SNr is closely associated with the gating of epileptic seizures in the brain (Iadarola and Gale, 1982; Garant and Gale, 1983; McNamara et al., 1983, 1984; Depaulis et al., 1994). The effects seen here of ketone bodies in DGNs may suggest that the opening of $\mathrm{K}_{\mathrm{ATP}}$ channels represent a general mechanism- under metabolic control—for tempering excitability during high-activity, epileptic-like states.

\section{References}

Aguilar-Bryan L, Bryan J (1999) Molecular biology of adenosine triphosphate-sensitive potassium channels. Endocr Rev 20:101-135.

Allen TG, Brown DA (2004) Modulation of the excitability of cholinergic basal forebrain neurones by $\mathrm{K}_{\mathrm{ATP}}$ channels. J Physiol 554:353-370.

Ashcroft FM, Gribble FM (1999) ATP-sensitive $\mathrm{K}^{+}$channels and insulin secretion: their role in health and disease. Diabetologia 42:903-919.

Ashford ML, Boden PR, Treherne JM (1990) Glucose-induced excitation of hypothalamic neurones is mediated by ATP-sensitive $\mathrm{K}^{+}$channels. Pflügers Arch 415:479-483.

Babenko AP, Gonzalez G, Aguilar-Bryan L, Bryan J (1998) Reconstituted human cardiac $\mathrm{K}_{\mathrm{ATP}}$ channels: functional identity with the native channels from the sarcolemma of human ventricular cells. Circ Res 83:1132-1143.

Baukrowitz T, Tucker SJ, Schulte U, Benndorf K, Ruppersberg JP, Fakler B (1999) Inward rectification in $\mathrm{K}_{\mathrm{ATP}}$ channels: a $\mathrm{pH}$ switch in the pore. EMBO J 18:847-853.

Ben-Ari Y, Krnjević K, Crépel V (1990) Activators of ATP-sensitive $\mathrm{K}^{+}$ channels reduce anoxic depolarization in CA3 hippocampal neurons. Neuroscience 37:55-60.

Benndorf K, Friedrich M, Hirche H (1991) Anoxia opens ATP regulated $\mathrm{K}^{+}$channels in isolated heart cells of the guinea pig. Pflugers Arch 419:108-110.

Bower MR, Buckmaster PS (2008) Changes in granule cell firing rates precede locally recorded spontaneous seizures by minutes in an animal model of temporal lobe epilepsy. J Neurophysiol 99:2431-2442.

Cook DL, Hales CN (1984) Intracellular ATP directly blocks $\mathrm{K}^{+}$channels in pancreatic B-cells. Nature 311:271-273.

Coulter DA, Carlson GC (2007) Functional regulation of the dentate gyrus by GABA-mediated inhibition. Prog Brain Res 163:235-243.

Dabrowski M, Larsen T, Ashcroft FM, Bondo Hansen J, Wahl P (2003) Potent and selective activation of the pancreatic beta-cell type $\mathrm{K}_{\mathrm{ATP}}$ channel by two novel diazoxide analogues. Diabetologia 46:1375-1382.

Depaulis A, Vergnes M, Marescaux C (1994) Endogenous control of epilepsy: the nigral inhibitory system. Prog Neurobiol 42:33-52.

Dunn-Meynell AA, Rawson NE, Levin BE (1998) Distribution and phenotype of neurons containing the ATP-sensitive $\mathrm{K}^{+}$channel in rat brain. Brain Res 814:41-54.

Garant DS, Gale K (1983) Lesions of substantia nigra protect against experimentally induced seizures. Brain Res 273:156-161.

Haller M, Mironov SL, Karschin A, Richter DW (2001) Dynamic activation of $K_{\text {ATP }}$ channels in rhythmically active neurons. J Physiol 537:69-81.

Heinemann U, Beck H, Dreier JP, Ficker E, Stabel J, Zhang CL (1992) The dentate gyrus as a regulated gate for the propagation of epileptiform activity. Epilepsy Res Suppl 7:273-280.

Henze DA, Wittner L, Buzsáki G (2002) Single granule cells reliably discharge targets in the hippocampal CA3 network in vivo. Nat Neurosci 5:790-795.

Iadarola MJ, Gale K (1982) Substantia nigra: site of anticonvulsant activity mediated by gamma-aminobutyric acid. Science 218:1237-1240.

Inagaki N, Tsuura Y, Namba N, Masuda K, Gonoi T, Horie M, Seino Y, Mizuta M, Seino S (1995) Cloning and functional characterization of a novel ATP-sensitive potassium channel ubiquitously expressed in rat tissues, including pancreatic islets, pituitary, skeletal muscle, and heart. J Biol Chem 270:5691-5694.

Jung MW, McNaughton BL (1993) Spatial selectivity of unit activity in the hippocampal granular layer. Hippocampus 3:165-182.

Kabakov AY (1998) Activation of $\mathrm{K}_{\mathrm{ATP}}$ channels by Na/K pump in isolated cardiac myocytes and giant membrane patches. Biophys J 75:2858-2867.

Karschin C, Ecke C, Ashcroft FM, Karschin A (1997) Overlapping distribution of $\mathrm{K}_{\mathrm{ATP}}$ channel-forming Kir6.2 subunit and the sulfonylurea receptor SUR1 in rodent brain. FEBS Lett 401:59-64.

Krnjević K, Ben-Ari Y (1989) Anoxic changes in dentate granule cells. Neurosci Lett 107:89-93.

Kyrozis A, Reichling DB (1995) Perforated-patch recording with gramicidin avoids artifactual changes in intracellular chloride concentration. J Neurosci Methods 57:27-35.

Liu X, Tilwalli S, Ye G, Lio PA, Pasternak JF, Trommer BL (2000) Morphologic and electrophysiologic maturation in developing dentate gyrus granule cells. Brain Res 856:202-212.

Lothman EW, Stringer JL, Bertram EH (1992) The dentate gyrus as a control point for seizures in the hippocampus and beyond. Epilepsy Res Suppl 7:301-313.

Ma W, Berg J, Yellen G (2007) Ketogenic diet metabolites reduce firing in central neurons by opening $\mathrm{K}_{\mathrm{ATP}}$ channels. J Neurosci 27:3618-3625.

McNamara JO, Rigsbee LC, Galloway MT (1983) Evidence that substantia nigra is crucial to neural network of kindled seizures. Eur J Pharmacol 86:485-486.

McNamara JO, Galloway MT, Rigsbee LC, Shin C (1984) Evidence implicating substantia nigra in regulation of kindled seizure threshold. J Neurosci 4:2410-2417.

Miki T, Nagashima K, Tashiro F, Kotake K, Yoshitomi H, Tamamoto A, Gonoi T, Iwanaga T, Miyazaki J, Seino S (1998) Defective insulin secretion and enhanced insulin action in $\mathrm{K}_{\mathrm{ATP}}$ channel-deficient mice. Proc Natl Acad Sci U S A 95:10402-10406.

Miki T, Liss B, Minami K, Shiuchi T, Saraya A, Kashima Y, Horiuchi M, Ashcroft F, Minokoshi Y, Roeper J, Seino S (2001) ATP-sensitive $\mathrm{K}^{+}$ channels in the hypothalamus are essential for the maintenance of glucose homeostasis. Nat Neurosci 4:507-512.

Nichols CG (2006) $\mathrm{K}_{\mathrm{ATP}}$ channels as molecular sensors of cellular metabolism. Nature 440:470-476.

Pelletier MR, Pahapill PA, Pennefather PS, Carlen PL (2000) Analysis of single $\mathrm{K}_{\mathrm{ATP}}$ channels in mammalian dentate gyrus granule cells. J Neurophysiol 84:2291-2301.

Pierrefiche O, Bischoff AM, Richter DW (1996) ATP-sensitive $\mathrm{K}^{+}$channels are functional in expiratory neurones of normoxic cats. J Physiol 494:399-409.

Podlogar M, Dietrich D (2006) Firing pattern of rat hippocampal neurons: a perforated patch clamp study. Brain Res 1085:95-101.

Schmidt-Hieber C, Jonas P, Bischofberger J (2004) Enhanced synaptic plasticity in newly generated granule cells of the adult hippocampus. Nature 429:184-187.

Seino S, Miki T (2003) Physiological and pathophysiological roles of ATPsensitive $\mathrm{K}^{+}$channels. Prog Biophys Mol Biol 81:133-176.

Tzingounis AV, Nicoll RA (2008) Contribution of KCNQ2 and KCNQ3 to the medium and slow afterhyperpolarization currents. Proc Natl Acad Sci U S A 105:19974-19979.

Yamada K, Ji JJ, Yuan H, Miki T, Sato S, Horimoto N, Shimizu T, Seino S, Inagaki N (2001) Protective role of ATP-sensitive potassium channels in hypoxia-induced generalized seizure. Science 292:1543-1546.

Zawar C, Plant TD, Schirra C, Konnerth A, Neumcke B (1999) Cell-type specific expression of ATP-sensitive potassium channels in the rat hippocampus. J Physiol 514:327-341. 